


\title{
Mudança organizacional em sistemas educacionais: uma compreensão à luz da análise de redes sociais
}

\author{
Organizational change in education systems: \\ an understanding by using of social network analysis \\ Cambio organizacional en sistemas educativos: \\ una comprensión usando análisis de redes sociales
}

\author{
Janssen Edelweiss Nunes Fernandes Teixeira* \\ ROBERT EVAN VERHINE**
}

\begin{abstract}
RESUMO - O presente estudo insere-se no campo de conhecimento das políticas públicas, considerando a implementação de políticas de cunho descentralizador orientadas para a melhoria da qualidade da educação, como um processo de mudança organizacional em sistemas educacionais. O objetivo geral é analisar as interferências das redes sociais de comunicação entre líderes das Diretorias Regionais de Educação, com sedes em Caetité e Brumado, Bahia, e dirigentes das escolas públicas estaduais, localizadas nessas cidades, nos processos de mudança organizacional observados nessas escolas. A metodologia utilizada para o alcance desse objetivo incluiu a aplicação de um instrumento para coleta de dados primários, envolvendo redes sociais compostas por 41 atores, além do tratamento e análise dos dados por meio dos softwares UCINET e NetDraw. A análise das estruturas das redes de comunicação investigadas sinaliza que existe uma tendência de facilitação do processo de mudança organizacional nas escolas públicas estaduais de Caetité, pela existência de redes sociais mais densas, centralizadas, conectadas e caracterizadas por relações mais intensas. Os dados revelam uma tendência de desenvolvimento de relações sociais para comunicação, em Caetité, que permitem o compartilhamento de experiências, além da discussão de possíveis estratégias para enfrentamento de diversos problemas que afetam a gestão escolar, o ensino e a aprendizagem.

Palavras-chave - Políticas públicas. Mudança organizacional. Autonomia escolar. Análise de redes sociais.
\end{abstract}

ABSTRACT - This study falls within the field of knowledge of public policies, considering the implementation of policies of decentralized nature, aimed at improving the quality of education as a process of organizational change in educational systems. This paper aims to analyze the interferences of the social networks of communication among the leaders of the Regional Directorate of Education located in Caetité and Brumado, Bahia, and directors of public state schools located in those cities in processes of organizational change observed in those schools. The methodology used in this investigation included the application of an instrument for primary data collection, involving social networks composed by 41 actors, as well as the processing and analysis of data through the software UCINET and NetDraw. The analyses of the structures of communication social networks investigated indicates that there is a tendency to facilitate the process of organizational change inherent to the implementation of policies aimed at strengthening school autonomy in the public state schools of Caetité, for the existence of denser, more centralized, connected and characterized by more intense relations. The data shows a tendency to development of communication relations in Caetitéthat allow the sharing of experiences and discussion of possible strategies for coping with various problems affecting the school management, teaching and learning.

Keywords - Public policy. Organizational change. School autonomy. Social network analysis.

RESUMEN - Este estudio se comprende dentro del campo del conocimiento de las políticas públicas, considera la implementación de políticas de tipo descentralizado y está dirigido a mejorar la calidad de la educación como proceso de cambio organizacional en los sistemas educativos. El trabajo pretende analizar las interferencias de las redes sociales de comunicación entre los dirigentes del Directorado Regional de Educación localizado en Caetité y Brumado, Bahia, y los directores de las escuelas estatales situadas en estas ciudades y que se encuentran en procesos de cambio organizacional. La metodología usada en esta investigación incluye la aplicación de un instrumento para la recolección de datos primariosde redes sociales compuestas por 41 actores, además del procesamiento y análisis de los datos a través del software UCINET and NetDraw. Los análisis de las estructuras de redes sociales de comunicación investigados indican que existe una tendencia a facilitar el proceso de cambio organizacional inherente a la implementación de políticas dirigidas a fortalecer la autonomía de los centros en las escuelas públicas estatales de Caetité, debido a la existencia de una red social más densa, centralizada, conectada y caracterizada por unas relaciones más intensas. Los datos muestran una tendencia a un desarrollo de las relaciones de comunicación de Caetité que permiten proponer experiencias y discusiones de posibles estrategias que hagan frente a los diversos problemas que afectan a la gestión de las escuelas, la docencia y el aprendizaje.

Palabras clave - Políticas Públicas. Cambio organizacional. Autonomía escolar. Análisis de redes sociales.

\footnotetext{
* Doutor em Administração de Empresas pela Universidade Federal da Bahia (Salvador, BA, Brasil) e Professor na Universidade Federal da Bahia (Salvador, BA, Brasil). E-mail: <janssen.teixeira@gmail.com>.

** Doutor em Educação pela Universidade de Hamburgo (Hamburgo, Alemanha) e Professor na Universidade Federal da Bahia. E-mail: <verhine@ufba.br>.
} 


\section{INTRODUÇÃO}

O presente artigo se apropriou dos temas da reforma do Estado e da descentralização de políticas públicas em diversas áreas, incluindo educação. Em adição, considerou a implementação de políticas para o fortalecimento da autonomia escolar como a materialização do movimento descentralizador na esfera educacional, bem como a busca da melhoria da qualidade da educação como um processo de mudança organizacional em curso nos sistemas educacionais brasileiros.

Este artigo foi elaborado com o objetivo de analisar as interferências das redes sociais de comunicação entre líderes das Diretorias Regionais de Educação (DIREC), com sedes em Caetité e Brumado, Bahia, e dirigentes das escolas públicas estaduais, localizadas nessas cidades, nos processos de mudança organizacional observados nessas escolas, inerentes à melhoria da qualidade da educação, nos primórdios da segundadécada do século XXI.

A realização deste estudo se justificou pela existência de uma lacuna na produção científica com base empírica sobre a interferência de redes sociais de liderança nos processos de mudança organizacional em curso em sistemas educacionais regionais, como ocorre nas escolas públicas estaduais de Caetité e Brumado, sob jurisdição das DIREC 24 e 19, com sedes nos citados municípios baianos, respectivamente, embora estudos já tenham sido realizados tratando de redes de escolas, de diretores de escolas, de professores, bem como de redes envolvendo as escolas e os pais de seus alunos. Estudos sobre redes de comunicação entre líderes regionais e dirigentes escolares, tratadas sob a perspectivas de processos de mudança organizacional e com base em evidências empíricas, não foram realizados (DALY; FINNIGAN, 2010).

Este artigo se divide em cinco seções, além desta introdução, apresentando, inicialmente, o quadro referencial teórico inerente aos conceitos centrais utilizados neste estudo. Em seguida, o objeto de estudo é apresentado. A quarta seção contempla a metodologia utilizada. Na penúltima parte, os dados coletados são analisados e interpretados à luz de argumentos encontrados na literatura especializada. Finalmente, as considerações finais são apresentadas.

\section{PERSPECTIVA ANALÍtiCA: REDES SOCIAIS E MUDANÇA ORGANIZACIONAL}

Considerando o objeto deste estudo, foi utilizado um referencial teórico que contempla a análise de redes sociais e as contribuições dessa perspectiva analítica para a compreensão de processos de mudança organizacional em sistemas educacionais, no contexto da implementação de políticas públicas para fortalecimento da autonomia escolar e do empreendimento de esforços para a melhoria da qualidade da educação ofertada.

É importante começar apresentando noções concernentes às políticas para fortalecimento da autonomia escolar, que se inserem no arcabouço mais amplo da reforma do Estado e da descentralização de políticas. Dentre os autores que contribuíram para a construção do quadro referencial utilizado neste artigo, Arretche (1999), Lubambo (2001) e Souza (2002) abordam, no âmbito mais abrangente da descentralização de políticas públicas, os fatores que têm força para influenciar a implementação dessas políticas. De forma um pouco mais específica, Martins (2001) trata de atributos estruturais que podem dificultar ou não a autonomia escolar. Ademais, Martins (2002), Alonso (2003) e Gawlik (2008) apontam como as instituições podem limitar a redistribuição de poder para a tomada de decisão dentro dos sistemas educacionais. Wohlstetter e Mohrman (1993), além de Briggs e Wohlstetter (1999), Carnoy e Marshall (2002) e Reis (2003), enumeram alguns requisitos para a implementação de políticas para fortalecimento da autonomia escolar, esclarecendo a relevância do desenvolvimento de capacidade para a tomada de decisão e a necessária transferência de poder dos órgãos centrais para as unidades de ensino.

Quanto às noções de capital social e análise de redes sociais, vale notar que, segundo Bourdieu (1986), o capital pode se apresentar sob as formas de capital econômico, cultural e social, sendo que a primeira modalidade pode ser convertida, com facilidade, em dinheiro, enquanto a segunda é mais frequentemente institucionalizada em qualificações educacionais. O capital social, por sua vez, é passível de conversão, sob certas condições, em capital econômico.

A teoria do capital social deriva da teoria geral do capital e tem sido difundida, nas décadas mais recentes, em estudos no âmbito da Sociologia, Ciência Política, Economia, Educação e Administração, cabendo registrar que muitas obras citam as noções seminais dos sociólogos Pierre Bourdieu (1986) e James Coleman (1988) sobre capital social. Enquanto o conceito de Bourdieu (1986) está fundamentado nas teorias da reprodução social e do poder, o de Coleman (1988) tem raízes estruturais e funcionalistas.

Para Coleman (1988), o capital social deve ser definido a partir das suas funções e, ao viabilizar o alcance de determinados fins, essa forma de capital também é tida como produtiva, da mesma forma que o capital físico e o capital humano.

A noção de capital social aderente ao objetivo desteestudo é aquela que enfatiza os recursos materiais e não materiais que indivíduos ou grupos podem acessar por meio de laços sociais. O conceito de capital social 
apropriado para a presente investigação é o que define essa forma de capital a partir dos recursos existentes em redes sociais de conhecimento mútuo, sendo os relacionamentos entre os atores dessas redes construídos socialmente. Tal conceito ressalta a relevância das redes sociais na criação e reprodução do capital social (ADLER; KWON, 2002; BOURDIEU, 1986; HOVART; WEININGER; LAREAU, 2003; LIN, 2001; TSAI; GHOSHAL, 1998).

Vale notar que o foco nas relações entre os atores das redes sociais, presente no conceito de capital social selecionado para esta investigação, viabiliza a utilização de uma perspectiva mais instrumental para os laços sociais entre indivíduos, aplicável a casos que envolvem a busca do alcance de metas coletivas (ADLER; KWON, 2002).

Com relação à perspectiva de análise de redes sociais utilizada na presente investigação, cabe ressaltar que a mesma possibilita novos níveis de explicações para perguntas típicas de estudos sociais, por meio de definições formais de aspectos do ambiente social, econômico e político. Os padrões ou regularidades nos relacionamentos entre unidades constituem o ambiente social, sob o ponto de vista da análise de redes sociais adotado nesteestudo (WASSERMAN; FAUST, 1998).

No presente estudo, considera-se análise de redes sociais como o conjunto de ferramentas, composto por objetos e relações entre eles, que se presta ao entendimento das estruturas sociais. Esses objetos são os atores sociais, são as posições das redes sociais, enquanto que as relações são os laços sociais, que se caracterizam pelas suas formas e conteúdos. A forma relacional diz respeito às propriedades das conexões entre os atores, enquanto os significados substantivos dessas conexões compõem o conteúdo relacional. A análise de redes sociais se dá a partir do desenvolvimento de modelos formais para representar determinadas características de comportamentos sociais do mundo real, de modo que esses modelos permitem ilustrar, muitas vezes, as estruturas sociais por meio de gráficos, usualmente identificados como sociogramas, contendo pontos e linhas, ou seja, atores e laços (KNOKE, 1990).

Dentre os tipos de redes sociais existentes, as redes de comunicação foram selecionadas para serem utilizadas neste artigo, uma vez que estão disponíveis na literatura especializada estudos recentes sobre as interferências desses tipos de redes em processos de mudança organizacional. As redes de comunicação são identificadas de acordo com as características dos seus conteúdos relacionais, isto é, segundo aquilo que flui ou que é trocado entre os atores nos seus laços sociais. Neste estudo, redes de liderança são aquelas compostas por atores envolvidos em tarefas fundamentais, que ocupam posições de destaque nas organizações (DALY; FINNIGAN, 2010; KNOKE, 1990; TSAI; GHOSHAL, 1998).
Este estudo considera que, no âmbito da análise de reformas educacionais, a colaboração entre atores escolares é central para o sucesso de processos voltados para a melhoria da educação. A lógica inerente a esse ponto de vista é que a discussão de problemas pelos atores leva-os a compartilhar lições e estratégias de enfrentamento de problemas, que são úteis para a melhoria da performance no sistema educacional. A análise de redes sociais, nesse sentido, pode ser utilizada para compreender a eficácia da mencionada colaboração entre atores envolvidos nas reformas educacionais (BARROSO, 1998; LIBÂNEO, 2004; PENUEL et al., 2006).

Do campo dos estudos organizacionais, o presente artigo se apropria de construções da teoria da contingência, como a que estabelece que analisar organizações enquanto organismos implica o entendimento das suas relações com o ambiente, assim como das suas relações internas. Por esse prisma, as organizações são consideradas sistemas abertos, de modo que, para sobreviver, elas precisam relacionar-se adequadamente com o seu meio ambiente. Nesse enfoque sistêmico, os processos de mudança organizacional podem ser considerados como tais adequações ao ambiente, de modo que a análise organizacional passa a envolver discussões em torno de interações dentro e fora das fronteiras das organizações, além do tratamento de requisitos sociais e ambientais somados àqueles de cunho mais técnico e administrativo (MORGAN，2007; TURNER; HALLENCREUTZ; HALEY, 2009).

Para Turner, Hallencreutz e Haley (2009), quando os processos de mudança organizacional são considerados segundo uma perspectiva sistêmica, fatores como padrões de relações interpessoais, atitudes e percepções passam a determinar, juntamente com outros elementos, o sucesso desses processos.

Com base no quadro referencial mencionado nos parágrafos anteriores, os processos de mudança organizacional em curso nas escolas estaduais, localizadas em Caetité e Brumado, Bahia, foram analisados pelo prisma das interferências das redes sociais de comunicação no suporte ou restrição aos esforços empreendidos para a melhoria da qualidade da educação ofertada nas mencionadas escolas. Variáveis inerentes à formarelacional das redes sociais entre líderes das DIREC, com sedes nas duas cidades em questão, e dirigentes escolares foram utilizadas para analisar os esforços desses atores, voltados para a melhoria do desempenho dos estudantes das escolas públicas em referência.

\section{O OBJETO DE ESTUDO}

$\mathrm{O}$ objeto deste estudo corresponde às redes sociais de comunicação entre líderes das DIREC, com sedes 
em Caetité e Brumado, Bahia, e dirigentes das escolas públicas estaduais, localizadas nessas cidades.

Vale notar que, na Bahia, a estrutura do sistema educacional estadual contempla, além da Secretaria da Educação, com sede na capital, Salvador, 33 DIREC, localizadas nessa capital e em municípios do interior. A descentralização refletida na estrutura do sistema educacional baiano foi concebida no contexto do reconhecimento, por parte do Governo da Bahia, da complexidade da oferta da educação no estado, bem como da necessidade de criar condições para a consolidação do papel do órgão central na definição de diretrizes gerais e políticas para a educação pública (BAHIA, 1997, 2010).

$\mathrm{Na}$ rede pública estadual da Bahia, as escolas estão vinculadas técnica e administrativamente às Diretorias Regionais, cujas estruturas comportam uma Diretoria Geral (Diretoria Regional de Educação) e uma Coordenação de Organização e Atendimento da Rede Escolar. A estrutura administrativa de uma escola pública típica do sistema educacional baiano conta, dependendo da quantidade de estudantes matriculados, com os seguintes profissionais: Diretor, Vice-Diretor e Secretário Escolar (BAHIA, 2010).

As DIREC têm um amplo elenco de competências, devidamente definido no regimento da Secretaria da Educação do Estado da Bahia (SEC), sendo que, de acordo com os propósitos deste artigo, cabe destacar as seguintes atribuições: orientar e acompanhar as unidades escolares no exercício de sua autonomia pedagógica, administrativa e financeira; além de orientar e acompanhar o processo de gestão participativa nas unidades escolares (BAHIA, 2010).

A DIREC 24 tem sede em Caetité, sendo que sob sua jurisdição também estão as redes de escolas estaduais localizadas em outros nove municípios do sudoeste baiano. Integram a estrutura da DIREC 24, além do Diretor Regional e do Coordenador de Organização e Atendimento da Rede Escolar, os seguintes líderes, que participaram da rede social inerente ao objeto de estudo aqui referido: Inspetor de Rede Física; Coordenador Financeiro; Gestor de Recursos Humanos;Supervisor Regional do Programa Todos pela Alfabetização (TOPA);Coordenador Local do Programa de Gestão da Aprendizagem Escolar (GESTAR);Professor Formador do Programa de Capacitação de Gestores (PROGESTÃO); além do Responsável pelo Festival Anual da Canção Estudantil - FACE (BAHIA, 2011a).

A equipe técnico-administrativa indicada acima interage com os dirigentes das escolas públicas sob jurisdição da DIREC 24, incluindo as quatro escolas estaduais que ofertam o ensino fundamental em Caetité e que, segundo dados do Anuário Estatístico da Educação da Bahia, de 2007, atendem 1.640 estudantes do ensino fundamental. As unidades de ensino em questão não terão os seus nomes identificados neste estudo, devido ao caráter central da confidencialidade dos atores nas análises de redes sociais.

Por outro lado, a DIREC 19 tem sede em Brumado e envolve outros 11 municípios sob sua jurisdição. Os seguintes líderes da estrutura dessa Diretoria Regional de Educação integraram a rede social inerente ao objeto de estudo em questão: Diretor Regional; Coordenador de Organização e Atendimento da Rede Escolar; Inspetor de Rede Física; Coordenador Pedagógico; Coordenador Financeiro; Gestor de Recursos Humanos; Supervisor Regional do TOPA; Coordenador Local do GESTAR; além do Professor Formador do PROGESTÃO (BAHIA, 2011a).

A equipe técnico-administrativa indicada acima interage com os dirigentes das escolas públicas sob jurisdição da DIREC 19, incluindo as três escolas estaduais que ofertam o ensino fundamental em Brumado e que, segundo dados do Anuário Estatístico da Educação da Bahia, de 2007, atendem 1.136 estudantes do ensino fundamental (BAHIA, 2009).

O critério básico utilizado para a escolha dos casos que compõem o objeto deste estudo foi a singularidade da situação envolvendo, primeiramente, o desempenho dos estudantes das escolas públicas estaduais localizadas em Caetité, vis-à-vis o desempenho médio apurado nas escolas públicas da Bahia, considerando os resultados do Índice de Desenvolvimento da Educação Básica (IDEB) para a $4^{\text {a }}$ série do ensino fundamental. De acordo com os últimos dados divulgados pelo Instituto Nacional de Estudos e Pesquisas Educacionais Anísio Teixeira (INEP), considerando as escolas da rede pública estadual e a $4^{\text {a }}$ série do ensino fundamental, o desempenho médio dos estudantes das escolas localizadas em Caetité, Bahia, foi igual a 4,7, tendo sido superior à média da Bahia, igual a 3,2. A média apurada em Caetité ficou próxima da média nacional, da ordem de 4,9, cabendo ressaltar que a Bahia foi a unidade da federação com IDEB mais baixo, naquele ano, série e rede. Vale destacar que esse resultado de Caetité foi o $3^{\circ}$ mais alto da Bahia, sendo que a rede estadual dessa cidade é maior do que as das outras duas cidades baianas com desempenho mais elevado, o que também foi considerado no critério para escolha desse caso (BRASIL, 2010).

Adicionalmente, a escolha de Brumado foi feita em função do desempenho médio dos estudantes de $4^{\mathrm{a}}$ série das escolas da sua rede pública estadual ter sido igual a 2,8 , segundo os últimos dados do INEP, ficando próximo da média baiana, além de ter sido inferior à média aferida nas escolas localizadas em Caetité, sendo que essas duas cidades são sedes de Diretorias Regionais de Educação e estão situadas na região do semiárido baiano. 
Caetité e Brumado são cidades vizinhas, com economias baseadas, até poucos anos atrás, na agricultura, e que somente agora diversificam-se com atividades industriais e de extrativismo mineral. O Índice de Desenvolvimento Humano Municipal (IDH-M) de Caetité, em 2000, igual a 0,673, não difere tanto do de Brumado, igual a 0,693. As redes estaduais de Caetité e Brumado são semelhantes nos tamanhos, pois englobam quatro e três escolas, que ofertam o ensino fundamental, atendendo 1.640 e 1.136 estudantes, respectivamente, de acordo com dados de 2007. Vale notar que os dirigentes escolares de todas essas sete unidades de ensino foram solicitados a responder o instrumento de coleta de dados (BAHIA, 2009; BRASIL, 2010).

Quanto à delimitação temporal, a razão para a realização deste estudo nos primórdios da segunda década do século XXI reside no período transcorrido deste o início da implementação da política para fortalecimento da autonomia escolar, na Bahia, em 2001. Ao longo de cerca de dez anos, a implementação dessa política desencadeou, por seu turno, os processos de mudança organizacional em curso nos sistemas educacionais escolhidos, voltado para a melhoria do desempenho dos estudantes das suas escolas públicas.

Dessa forma, tem-se dois casos para estudo, com características semelhantes, inclusive em termos socioeconômicos, em que, contudo, os desempenhos dos estudantes de $4^{\mathrm{a}}$ série das escolas estaduais de cada caso diferem diametralmente. Em um dos casos, o desempenho dos estudantes está acima do desempenho médio do estado como um todo e, em outro, está próximo desse desempenho médio, que é o mais baixo do Brasil.

\section{Metodologia}

As etapas da metodologia utilizada para a elaboração deste artigo foram as seguintes: delimitação das fronteiras das redes sociais sob estudo, isto é, determinação dos conjuntos de atores envolvidos nessas redes; coleta de dados (evidências); armazenamento dessas evidências em arquivos eletrônicos e em banco de dados; tratamento e análise dos dados; além da própria preparação do artigo.

A primeira etapa da metodologia empregada é de fundamental importância para um estudo que se insere no âmbito da análises de redes sociais. Antes de coletar qualquer dado sobre uma determinada rede social, é preciso identificar que atores são relevantes e serão incluídos nessa rede e, consequentemente, nas análises da mesma. Em alguns estudos, a determinação das fronteiras de uma rede social não é tão óbvia e imediata, dada a natureza da realidade social envolvida (WASSERMAN; FAUST, 1998).
Quanto à coleta de evidências, vale notar que um conjunto de técnicas foi empregado para tal fim, incluindo pesquisa documental, aplicação de questionário para levantamento de dados sobre as redes de liderança nas DIREC 24 e 19, além da condução de entrevistas semiestruturadas com alguns líderes envolvidos com os casos. O emprego dessas técnicas variadas viabilizou a investigação profunda e exaustiva do objeto, como defendem Martins (2006) e Yin (2005).

A coleta de dados começou com a exploração de documentos relacionados com a implementação da política para fortalecimento da autonomia escolar nos âmbitos das DIREC com sedes em Caetité e Brumado, incluindo o marco legal aplicável e os instrumentos de divulgação disponíveis em meios digitais. Esses documentos foram utilizados para corroborar as evidências levantadas a partir de outras fontes. Tal exploração inicial foi necessária para o conhecimento do objeto de estudo por parte do pesquisador, que, conforme defendido por Wasserman e Faust (1998), é central para a determinação das fronteiras das redes sociais sob análise.

Contudo, a principal técnica utilizada para coletar os dados para este estudo consistiu na aplicação de um instrumento para identificação e mapeamento das redes sociais de comunicação entre líderes das DIREC com sedes em Caetité e Brumado e dirigentes das escolas públicas estaduais localizadas nessas cidades. Esse instrumento inclui perguntas ou assertivas para identificação e mapeamento das estruturas e conteúdos das redes sociais em pauta, além de itens para identificação dos respondentes e das escolas envolvidas na análise, que não serão, contudo, revelados, neste documento.

$\mathrm{O}$ instrumento para coleta de dados foi elaborado para arguir os respondentes acerca das suas relações com os demais líderes envolvidos nas redes sociais sob investigação, de forma que eles pudessem avaliar tais relacionamentos segundo escalas que denotam a qualidade dos laços sociais. Dessa forma, procurou-se atender a um dos requisitos básicos da análise de redes sociais, segundo Knoke (1990), Wasserman e Faust (1998), além de Cross e Parker (2004), que versa sobre o fato de que esse tipo de análise pressupõe a identificação dos objetos e das relações entre eles.

Sobre a questão fundamental da delimitação das fronteiras das redes sociais sob estudo, vale destacar as entrevistas iniciais que foram conduzidas com os Diretores Regionais de Educação estabelecidos em Caetité e Brumado, para identificar os líderes educacionais que integrariam essas redes. Começando pela DIREC 24, em Caetité, foram obtidos os nomes e as funções dos diretores e vice-diretores das escolas da rede estadual que ofertam o ensino fundamental, na sede dessa Diretoria Regional, bem como dos dirigentes dessa DIREC, que, segundo 
as competências regimentais, ${ }^{1}$ devem interagir com os líderes escolares. O mesmo foi feito, em seguida, na sede da DIREC 19, em Brumado. Não houve nenhuma razão específica para iniciar as entrevistas em Caetité, que não a logística para deslocamento do pesquisador, que foi quem coletou todos os dados utilizados nesteartigo.

A partir da realização dessa primeira etapa dos procedimentos metodológicos, foi possível identificar os atores e, assim, delimitar as fronteiras das duas redes sociais sob estudo, uma em cada DIREC.

A criticidade da confidencialidade dos atores, nos estudos envolvendo redes sociais, é destacada por Cross e Parker (2004), além de Penuel e outros (2006). Cross e Parker (2004) defendem o uso de três níveis de abordagem para o tratamento dessa questão, sendo um deles o que preserva integralmente as identidades dos atores, que foi a abordagem adotada nesta análise. Nesteartigo, os atores e as escolas em que alguns deles atuam foram codificados(as), quando da realização da etapa de tratamento de dados.

Ao todo, 41 atores foram identificados, sendo 21 deles líderes das redes da DIREC 24, e os 20 restantes, das redes da DIREC 19. Desses atores, 18 são dirigentes lotados nas sedes das Diretorias Regionais, sendo 9 em cada uma delas. Os demais atores, 23, são diretores de escolas, sendo 12 de unidades de ensino localizadas em Caetité, além de 11 de escolas de Brumado. Diretores de 7 escolas foram identificados, sendo quatro delas localizadas em Caetité e as outras três, em Brumado.

Vale notar que os dados de redes sociais diferem daqueles utilizados na maioria das pesquisas sociais e comportamentais, por consistirem de uma ou mais relações medidas entre um conjunto de atores. Dados desse tipo podem ser estudados em múltiplos níveis de análise, a saber: atores, pares de atores (díades), tríades, subconjuntos de mais do que três atores, ou as redes em suas totalidades (HANNEMAN; RIDDLE, 2005; WASSERMAN; FAUST, 1998).

Em termos da forma relacional, duas propriedades das relações afetam os tipos de medidas que podem ser realizadas em análises de redes sociais, que são a direcionalidade da relação e o fato de a mesma ser dicotomizada ou valorada. Em uma relação direcional, um laço entre dois atores tem uma origem e um destino. Relações dicotomizadas são aquelas codificadas exclusivamente pela presença ou ausência do laço entre o par de atores, enquanto as relações valoradas têm os seus laços assumindo uma gama de valores que indicam, normalmente, as suas forças, intensidades ou frequências. Usualmente, as relações dicotomizadas assumem valores zero - ausência da relação - ou um, que indica a presença do laço (HANNEMAN; RIDDLE, 2005; WASSERMAN; FAUST, 1998).
Os dados coletados em campo foram, na etapa seguinte da metodologia, armazenados em bases de dados do software UCINET. ${ }^{2}$ Cabe registrar que existe uma quantidade considerável de softwares disponíveis para auxiliar os pesquisadores envolvidos com análises de redes sociais, sendo que alguns deles combinam recursos para análises quantitativas com funcionalidades para desenho de gráficos das redes, enquanto outros especializam-se em uma dessas duas vertentes. O software UCINET foi escolhido para os propósitos metodológicos desteestudo por permitir as medidas da forma relacional, bem como pelo fato de ser um dos mais utilizados nas investigações do campo da análise de redes sociais. Em adição, é importante explicitar que o software escolhido para a geração dos sociogramas das redes referenciadas neste artigo foi o NetDraw, ${ }^{3}$ que, analogamente ao UCINET, é um dos mais difundidos nas análises de redes sociais (BORGATTI; EVERETT; FREEMAN, 2002; DALY; FINNIGAN, 2010).

\section{COMPREENDENDO PROCESSOS DE MUDANÇA ORGANIZACIONAL PELO PRISMA DA FORMA RELACIONAL}

De acordo com Hanneman e Riddle (2005), a perspectiva de redes sociais viabiliza análises em múltiplos níveis de complexidade, sendo a noção de conexão uma das mais utilizadas nos métodos de análises de redes sociais. Atores de redes com mais conexões estão expostos a informações em maiores volumes e diversidades. Por outro lado, atores com mais conexões podem, geralmente, ser mais influentes que ou influenciados por seus pares. Informações úteis podem ser mais rapidamente disseminadas em redes com taxas mais altas de conexão, que, também, tendem a mobilizar com mais facilidade os seus recursos, além de viabilizar um maior conjunto de perspectivas para solucionar os seus problemas (CROSS; PARKER, 2004; HANNEMAN; RIDDLE, 2005).

Cross e Parker (2004) explicam como interpretar os gráficos que ilustram redes sociais. Os nódulos, muitas vezes representados por pequenos círculos, quadrados ou triângulos, representam os atores sociais. Uma linha ligando dois atores representa um relacionamento entre eles e, em alguns casos, como nas redes ilustradas nos gráficos deste artigo, as pontas das setas indicam as direções dessa relação. Uma díade é representada por um par de atores devidamente conectados por uma linha em um gráfico.

Os sociogramas apresentados adiante (ver Figuras 1 e 2), gerados por meio do software NetDraw, ilustram, respectivamente, as redes de comunicação mapeadas nas DIREC 24 e 19. Percebe-se, com clareza, a diferença entre 
as estruturas dessas duas redes, sendo a rede da DIREC 24 mais densa. Adicionalmente, esses sociogramas revelam que todos os 21 e 20 atores das respectivas redes estão conectados com pelo menos um dos seus pares, o que por si só já garante o caráter de conectividade das mesmas. De fato, na esfera da análise de redes sociais, diz-se que uma rede é conectada quando todos os seus atores são alcançáveis por algum caminho - bidirecional ou unidirecional (CROSS; PARKER, 2004; HANNEMAN; RIDDLE, 2005; WASSERMAN; FAUST, 1998).

É fácil perceber, ainda, que atores aparecem mais no centro do que na periferia das redes ilustradas. Os sociogramas em questão ilustram, ainda, que o centro da rede da DIREC 24 é composto por um número maior de atores com muitas relações do que o núcleo da respectiva rede da DIREC 19. Cabe esclarecer que os softwares geradores de sociogramas utilizam algoritmos que posicionam, geralmente, os atores com as maiores quantidades de relações nos centros das redes, deixando aqueles com menos laços nas posições periféricas. Em adição, esses programas posicionam, usualmente, atores com quantidades similares de relações próximos uns dos outros (BORGATTI et al., 2009; CROSS; PARKER, 2004).

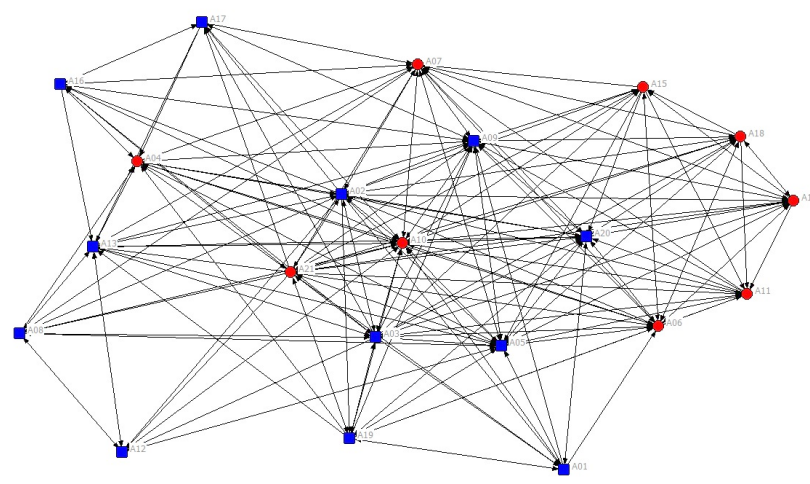

Figura 1 - Rede de comunicação mapeada na DIREC 24 Fonte: própria.

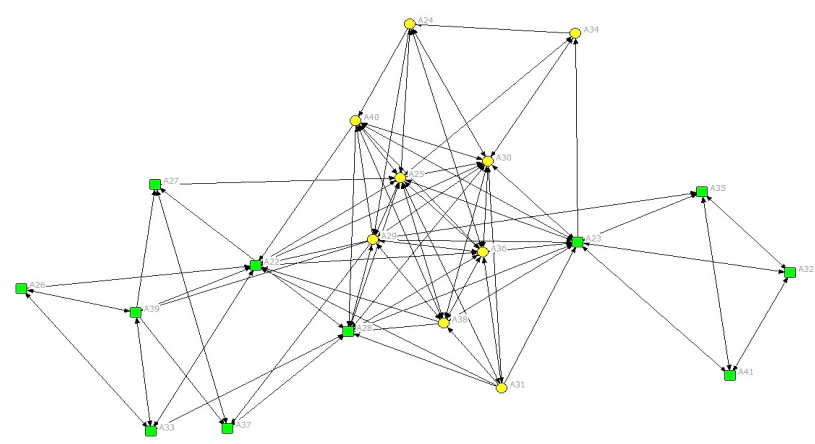

Figura 2 - Rede de comunicação mapeada na DIREC 19 Fonte: própria.
Em outras palavras, três das variáveis mais comuns nas análises de redes sociais, quais sejam densidade, conectividade e centralidade podem ser analisadas visualmente, por meio dos sociogramas, o que é um ponto forte desse instrumento. Mais adiante, as análises quantitativas viabilizadas pelo uso do UCINET corroborarão os achados desta interpretação visual das redes em pauta.

Concluída a etapa de interpretação visual dos sociogramas das redes de comunicação mapeadas nas DIREC 24 e 19, o próximo passo deste estudo consiste na análise quantitativa das interferências dessas redes sociais, sob o prisma da estrutura relacional, nos processos de mudança organizacional observados nas escolas dessas Diretorias Regionais. Para tanto, o software UCINET foi utilizado para obtenção das medidas de algumas propriedades das formas relacionais das redes em questão.

A densidade de uma rede social é dada pelo quociente entre as quantidades de laços observados e laços possíveis, quando a rede é dicotomizada, ou seja, quando as suas relações refletem exclusivamente as presenças (valores iguais a um) ou ausências dos laços (valores iguais a zero). Nas redes dicotomizadas, a densidade varia de zero (quando nenhuma relação é observada) a um (quando todas as relações possíveis são observadas). A quantidade de laços possíveis de uma rede direcionada de $k$ atores é calculada por $k *(k-1)$.

Por outro lado, quando uma rede social direcionada possui relações valoradas, isto é, com medidas que representam determinadas características para além da presença ou ausência do laço, a densidade corresponde ao valor médio das relações, que, quase sempre, é a média da força dessas relações. Nesses casos, a densidade pode assumir valores maiores do que um (WASSERMAN; FAUST, 1998).

Nenhuma das duas redes sociais investigadas foi mapeada a partir de dados dicotomizados, isto é, as perguntas ou assertivas do instrumento de levantamento de evidências que foram utilizadas para identificação das mesmas implicaram a coleta de dados que assumiram mais do que dois valores. Dessa forma, os dados coletados em campo serviram para identificar redes sociais valoradas. Durante a etapa de tratamento desses dados, asrespectivas redes tiveram as suas relações convertidas em valores dicotômicos, a fim de viabilizar as medidas das suas densidade. O software UCINET foi utilizado para transformar as relações sociais valoradas em relações dicotômicas, a partir de uma de suas funcionalidades.

Os dados revelam, com o auxílio do software UCINET, que as redes sociais de comunicação mapeadas na DIREC 24 são mais densas do que as respectivas redes identificadas na DIREC 19, corroborando as conclusões das análises visuais dos sociogramas dessas redes, tal 
qual explicitado anteriormente. É relevante destacar que as redes sociais investigadas possuem tamanhos semelhantes, uma vez que o tamanho de uma rede é dado pela sua quantidade de atores e, nos casos estudados, as redes da DIREC 19 têm tamanho 20 e as da DIREC 24, tamanho 21. Os próximos parágrafos contemplam uma interpretação desses dados à luz da teoria da análise de redes sociais.

Os valores das densidades das redes de comunicação valoradas observadas refletem as forças das relações de comunicação mapeadas nas DIREC 24 e 19, que foram, respectivamente, iguais a 1,3048 e 0,9921 , denotando laços mais fortes na rede mapeada na Diretoria Regional com sede em Caetité.

No mapeamento da rede de comunicação da DIREC 19, foram observadas 121 relações, dentre as 380 possíveis, daí o índice 0,3184 de densidade da rede dicotomizada. $\mathrm{Na}$ identificação da rede de comunicação da DIREC 24, foram observados 233 laços, dentre os 420 possíveis, implicando a densidade de 0,5548 da rede dicotomizada. Esses números revelam que mais da metade dos laços possíveis foram observados na rede de comunicação da DIREC 24 (sede em Caetité), contra menos de um terço daqueles possíveis, no caso da rede de comunicação da DIREC 19. Nessas duas redes sociais, as quantidades de relações possíveis são:

- DIREC 24: quantidade de laços possíveis $=21 \times 20=420$; - DIREC 19: quantidade de laços possíveis $=20 \times 19=380$.

Portanto, os dados revelam que a rede de comunicação da DIREC 24 não somente é mais densa do que a rede da DIREC 19 em termos das quantidades de laços observados, conforme medidas de densidade das redes dicotomizadas, como também da força dos mesmos, segundo medidas de densidade das redes valoradas.
Por outro lado, Hanneman e Riddle (2005) explicam que Linton Freeman, que é um dos criadores do UCINET, desenvolveu uma série de algoritmos para calcular as medidas de centralidade de redes sociais. Uma dessas medidas é a centralização geral do gráfico de uma rede, calculada com base em uma rede teórica com a maior centralização possível, que é uma rede do tipo estrela. Nesse tipo de rede, um ator (a estrela) tem grau igual ao número total de atores menos um, enquanto todos os demais têm grau igual a um. Linton Freeman definiu a medida de centralização geral para expressar a variação entre os graus dos atores de uma rede sob investigação como um percentual dos graus de uma rede estrela de mesmo tamanho. No caso da rede de comunicação da DIREC 24, a centralização geral do grau de saída é $46,75 \%$ desse valor teórico máximo da rede estrela de mesmo tamanho. A centralização geral do grau de entrada é, também, igual a $46,75 \%$, mas isso não é uma regra. Dessa forma, pode-se concluir que há uma centralização moderada na rede em questão, pois a medida geral é praticamente a metade da medida máxima possível. Em outras palavras, essa medida sinaliza a moderada capacidade de geração de poder por parte da rede de comunicação da DIREC 24.

De fato, Hanneman e Riddle (2005) destacam que a análise de redes sociais possibilita uma perspectiva distinta para tratamento de um dos aspectos mais importantes da estrutura social, que é o poder. Para esses autores, essa perspectiva diz respeito ao fato do poder de um determinado ator emanar das suas relações com os demais atores sociais, ao invés de ser um atributo individual. Segundo essa perspectiva, as variações nos padrões de relações entre atores de uma rede social serve para analisar os diferentes níveis de poder desses atores.

Tabela 1 - Estatística descritiva da centralidade da rede de comunicação da DIREC 24

\begin{tabular}{lcccc}
\hline \multicolumn{1}{c}{ Estatística descritiva } & Grau de saída & Grau de entrada & $\begin{array}{c}\text { Grau de saída } \\
\text { padronizado }\end{array}$ & $\begin{array}{c}\text { Grau de entrada } \\
\text { padronizado }\end{array}$ \\
\hline Média & 11,095 & 11,095 & 55,476 & 55,476 \\
Desvio padrão & 4,649 & 4,607 & 23,243 & 23,037 \\
Soma & 233,00 & 233,00 & 1165,00 & 1165,00 \\
Variância & 21,610 & 21,229 & 540,249 & 530,726 \\
Mínimo & 4,00 & 6,00 & 20,00 & 30,00 \\
Máximo & 20,00 & 20,00 & 100,00 & 100,00 \\
Quantidade de observações & 21 & 21 & 21 & 21 \\
Centralização da rede (segundo grau de saída) & & $46,75 \%$ & $46,75 \%$ \\
Centralização da rede (segundo grau de entrada) & & & \\
\hline
\end{tabular}

Fonte: própria. 
Segundo Hanneman e Riddle (2005) e de acordo com a perspectiva mencionada acima, um indivíduo tem poder porque tem a capacidade de dominar outros e, dessa forma, na esfera da análise de redes sociais, o poder de um ego é dependente dos alter. Por outro lado, uma vez que o poder é uma consequência dos padrões das relações entre os atores de uma rede, a quantidade de poder varia, em distintas estruturas sociais, justamente em função dessas estruturas. Dessa forma, redes pouco densas não são fontes de muito poder, ao passo em que redes com muitas relações sociais têm potencial para gerar mais poder.

A Tabela 2 reflete a estatística descritiva da medida de centralidade da rede de comunicação mapeada na DIREC 19. Em média, os atores dessa rede têm grau 6, o que não é expressivo, considerando que essa rede tem 20 atores. Percebe-se, também, que o intervalo de variação das medidas dos graus de entrada (entre 2 e 12) é um pouco maior do que o de saída (entre 2 e 11), ao mesmo tempo em que há maior variação (desvio padrão e variância) entre os atores em termos do grau de entrada do que de saída. O que a análise dos valores do desvio padrão e variância da Tabela 2 revela é que os atores da rede em questão são mais homogêneos em termos do grau de saída - leia-se influência - do que do grau de entrada prestígio -, ao contrário do caso da rede de comunicação da DIREC 24. Adicionalmente, os dados da Tabela 2 demonstram uma medida de centralização geral da rede em pauta da ordem de $27,42 \%$ (grau de saída) e 32,96\% (grau de entrada). Nas duas esferas (laços de saída e de entrada), a centralização geral da rede de comunicação da DIREC 19 é inferior a 1/3 (um terço) do valor teórico máximo da rede estrela de mesmo tamanho. Em outras palavras, pode-se concluir que há uma centralização fraca na rede em questão, isto é, que há uma baixa capacidade de geração de poder por parte dessa rede.
Comparando as medidas de centralização geral das redes de comunicação mapeadas nas DIREC 24 e 19, percebe-se que a rede da Diretoria com sede em Caetité é mais centralizada (medidas iguais a $46,75 \%$, tanto para saída, quanto para entrada).

Na rede de comunicação da DIREC 24, oito atores (quase a metade do total) têm elevado prestígio, isto é, possuem grau de entrada padronizado igual ou superior a 75 (setenta e cinco), contra nenhum caso na respectiva rede da DIREC 19, o que sinaliza que quase a metade dos atores da rede de comunicação de Caetité é composta por líderes muito procurados pelos seus pares para fins de comunicação. Já na rede da DIREC 19, nenhum ator encontra-se em uma posição de prestígio tão destacada (alta procura pelos demais atores, na esfera da comunicação), em termos da medida do grau de entrada padronizado.

\section{CONSIDERAÇÕES FINAIS}

Os argumentos encontrados na literatura especializada permitiram conceber o seguinte raciocínio: visando ao alcance do objetivo de melhorar a qualidade da educação dentro das suas áreas de atuação, em um novo contexto de implantação de políticas para fortalecimento da autonomia escolar, o que caracteriza um evidente processo de mudança organizacional nos sistemas de ensino, os dirigentes escolares e líderes regionais de educação tendem a desenvolver relações sociais para comunicação que lhes permita compartilhar experiências, além de discutir possíveis estratégias para enfrentar os diversos problemas que afetam a gestão escolar, o ensino e a aprendizagem.

A análise conjunta da densidade, centralidade, intensidade e conectividade das redes de comunicação

Tabela 2 - Estatística descritiva da centralidade da rede de comunicação da DIREC 19

\begin{tabular}{lcccc}
\hline \multicolumn{1}{c}{ Estatística descritiva } & Grau de saída & Grau de entrada & $\begin{array}{c}\text { Grau de saída } \\
\text { padronizado }\end{array}$ & $\begin{array}{c}\text { Grau de entrada } \\
\text { padronizado }\end{array}$ \\
\hline Média & 6,050 & 6,050 & 31,842 & 31,842 \\
Desvio padrão & 3,024 & 3,339 & 15,918 & 17,573 \\
Soma & 121,00 & 121,00 & 636,842 & 636,842 \\
Variância & 9,148 & 11,148 & 253,393 & 308,795 \\
Mínimo & 2,00 & 2,00 & 10,526 & 10,526 \\
Máximo & 11,00 & 12,00 & 57,895 & 63,158 \\
Quantidade de observações & 20 & 20 & 20 & 20 \\
Centralização da rede (segundo grau de saída) & & $27,42 \%$ & $32,96 \%$ \\
Centralização da rede (segundo grau de entrada) & & & \\
\hline
\end{tabular}

Fonte: própria. 
observadas nas DIREC 24 e 19, além dos IDEB das escolas públicas estaduais de Caetité (sede da DIREC 24) e Brumado (sede da DIREC 19), na 4a série, em 2009, sinaliza que existe uma tendência do raciocínio acima estar acontecendo, de formas distintas, nos dois casos estudados. A tendência é que as redes de comunicação que envolvem os dirigentes das escolas públicas estaduais de Caetité, por serem mais densas que as redes de líderes educacionais de Brumado, estejam facilitando o processo de mudança organizacional inerentes à implementação das políticas de cunho descentralizante, voltadas para o fortalecimento da autonomia escolar, e, assim, estejam aumentando a possibilidade de sucesso desse processo.

As medidas de densidade das redes de comunicação valorada mapeadas nas DIREC 24 e 19, que são iguais, respectivamente, a 1,3048 e 0,9921 , indicam que, provavelmente, a velocidade com que as informações são difundidas entre os atores da rede social identificada na Diretoria Regional com sede em Caetité é maior do que no caso da rede de Brumado, o mesmo acontecendo com o volume de capital social que os atores daquela primeira rede podem gerar a partir das relações sociais, que é um dos argumentos desenvolvidos por Hanneman e Riddle (2005). As relações entre os atores são cruciais para o sucesso de reformas voltadas para a melhoria educacional, uma vez que a discussão de problemas pelos mesmos viabiliza o compartilhamento de lições e estratégias para enfrentamento de problemas, conforme defendido por Penuel e outros (2006). No âmbito dos casos estudados, é possível que tal compartilhamento esteja acontecendo de forma mais efetiva nas redes de liderança de Caetité.

As análises das medidas de centralidade conduziram este estudo à identificação de tendências semelhantes. No caso da rede de comunicação da DIREC 24, a centralização geral dos graus de saída e de entrada é $46,75 \%$, contra uma centralização geral da rede da DIREC 19 da ordem de 27,42\% (grau de saída) e 32,96\% (grau de entrada). É possível que, no caso da rede mapeada em Caetité, os dirigentes escolares e líderes regionais de educação com maior potencial de influência sobre os atores menos centrais estejam encontrando mais facilidade para compartilhar experiências exitosas e discutir possíveis estratégias para enfrentar diversos problemas que afetam a gestão escolar, o ensino e a aprendizagem. A literatura especializada associa o caráter de centralidade de uma rede social às noções de poder, influência e prestígio. Dessa forma, pode-se concluir que a capacidade de geração de poder por parte dos atores das redes sociais mapeadas na DIREC 24 é maior do que no caso de Brumado. Adicionalmente, vale notar que a centralidade de uma rede serve para sinalizar as posições mais propícias à canalização dos fluxos de recursos dessa rede, aumentando a sua eficiência, como defendem Hanneman e Riddle (2005).

A análise das medidas de intensidade das redes sociais está imbricada com a análise das medidas de densidade dessas redes. Os dados revelam uma tendência da rede de comunicação mapeada em Caetité, por terlaços sociais mais fortes que a rede de líderes educacionais de Brumado, estar facilitando o processo de mudança organizacional inerente à implementação das políticas de cunho descentralizante, voltadas para o fortalecimento da autonomia escolar, e, assim, estar aumentando a possibilidade de sucesso desse processo. A literatura destaca que a presença de laços sociais fortes sinaliza organizações caracterizadas por atores sociais com mais iniciativa, bem como por maior facilidade para sustentabilidade de mudanças bem-sucedidas.

Com base no que foi exposto nos parágrafos anteriores, conclui-se que existe coerência no raciocínio de que quanto maiores as medidas de densidade, centralidade, intensidade e conectividade das redes de comunicação entre líderes de DIREC e dirigentes escolares maiores as possibilidades de sucesso dos processos de mudança organizacional nas escolas envolvidas nessas redes, inerentes à melhoria da qualidade da educação.

\section{REFERÊNCIAS}

ADLER, Paul S.; KWON, Seok-Woo.Social capital: prospects for a new concept. Academy of Management Review, Briarcliff Manor, v. 27, n. 1, 2002.

ALONSO, Myrtes. Autonomia da escola e participação. In: VIEIRA, Alexandre Thomaz; ALMEIDA, Maria Elizabeth Bianconcini de; ALONSO, Myrtes (Org.). Gestão educacional e tecnologia. São Paulo: Avercamp, 2003. p. 85-97.

ARRETCHE, Marta. Políticas sociais no Brasil: descentralização em um estado federativo. Revista Brasileira de Ciências Sociais, São Paulo, v. 14, n. 40, jun. 1999.

BAHIA. Decreto ${ }^{\circ}$ 6.212, de 14 de fevereiro de 1997. Define critérios para a organização administrativa das Diretorias Regionais de Educação e unidades escolares da rede estadual de ensino público. Diário Oficial do Estado da Bahia, Poder Executivo, Salvador, 15 fev. 1997.

Anuário estatístico da educação da Bahia - 2007. Salvador: SEC, 2009.

Regimento da Secretaria da Educação. Salvador: SEC, 2010. Disponível em: $<$ http://www.educacao.institucional. ba.gov.br/node/65>. Acesso em: 26 dez. 2010.

Diretoria Regional de Educação 24. Equipe da DIREC 24. Salvador: SEC, 2011a. Disponível em: <http:// www.direc24.com.br/direc24.php>. Acesso em: 3 jan. 2011.

BARROSO, João. O reforço da autonomia das escolas e a flexibilização da gestão escolar em Portugal. In: FERREIRA, Naura Syria Carapeto (Org.). Gestão democrática da educação: atuais tendências, novos desafios. São Paulo: Cortez, 1998. p. 11-32. 
BORGATTI, Stephen P.; EVERETT, M.; FREEMAN, L. UCINET for Windows: software for social network analysis. Harvard: Analytic Technologies, 2002.

BORGATTI, Stephen P. et al. Network analysis in the social sciences. Science, Washington, n. 323, fev. 2009. Disponível em: $<$ http://www.sciencemag.org/cgi/content/full/323/5916/892>. Acesso em: 14 dez. 2010.

BOURDIEU, Pierrre. The Forms of capital. In: RICHARDSON, J. G. Handbook of theory and research for the sociology of education. New York: Greenwood, 1986.

BRASIL.Ministério da Educação. Estatísticas do IDEB. Brasília, DF: [s.n.], 2010. Disponível em: <http://portalideb. inep.gov.br/index.php?option=com_content $\&$ view $=$ article $\&$ id $=43 \&$ Itemid $=7>$. Acesso em: $26 \mathrm{dez} .2010$.

BRIGGS, Kerri L.; WOHLSTETTER, Priscilla. Key elements of a successful school-based management strategy. [s.l.: s.n.], 1999. Disponível em: <http://www.usc.edu/dept/education/ cegov/publications/briggsandwohlstetter1999.pdf>. Acesso em: 26 abr. 2009.

CARNOY, Martin; MARSHALL, Jeffery. Preliminary evaluation of MEC/Fundescola's School Development Plan (PDE) experience: student achievement, attendance, attainment, degree of implementation and cost-benefit analysis. Washington, DC: [s.n.], 2002.

COLEMAN, James S. Social capital in the creation of human capital. American Journal of Sociology, Chicago, v. 94, n. S1, 1988.

CROSS, Rob; PARKER, Andrew. The hidden power of social networks: understanding how work really gets done in organizations. Boston: Harvard Business School Publishing Corporation, 2004.

DALY, Alan J.; FINNIGAN, Kara S. A bridge between worlds: understanding network structure to understand change strategy. Journal of Educational Change, Dordrecht, v. 11, n. 2, 2010.

GAWLIK, Marytza A. Breaking loose: principal autonomy in charter and public schools. Educational Policy, Thousand Oaks, v. 22, n. 6, 2008.

HANNEMAN, Robert A.; RIDDLE, Mark. Introduction to social network methods. Riverside, CA: University of California, 2005. Disponível em: <http://faculty.ucr. edu/ hanneman/>. Acesso em: 07 ago. 2011.

HOVART, Erin McNamara; WEININGER, Elliot B.; LAREAU, Annette. From social ties to social capital: class differences in the relations between schools and parent networks. American Educational Research Journal, Washington, v. 40, n. 2, 2003.

KNOKE, David. Political networks: the structural perspective. Cambridge: Cambridge University Press, 1990.

LIBÂNEO, José Carlos. Organização e gestão da escola: teoria e prática. 5. ed. Goiânia: Alternativa, 2004.

LIN, N. Social capital: a theory of social structure and action. Cambridge: Cambridge University Press, 2001.

LUBAMBO, Cátia Wanderey. A descentralização do Estado no Brasil. In: LIMA, Marcos Costa (Org.). O lugar da América do Sul na nova ordem mundial. São Paulo: Cortez, 2001. p. 199-218.
MARTINS, Ângela Maria. A descentralização como eixo das reformas do ensino: uma discussão da literatura. Educação \& Sociedade, Campinas, v. 22, n. 77, dez. 2001.

. Autonomia e educação: a trajetória de um conceito. Cadernos de Pesquisa, São Paulo, n. 115, mar. 2002. Disponível em: <http://www.scielo.br/scielo.php?script=sci arttext\&pid=S0100-15742002000100009\&lng=en\&nrm=iso $>$. Acesso em: 19 abr. 2009.

MARTINS, Gilberto de Andrade. Estudo de caso: uma estratégia de pesquisa. São Paulo: Atlas, 2006.

MORGAN, Gareth. Imagens da organização. Tradução de Cecília Whitaker Bergamini e Roberto Coda. São Paulo: Atlas, 2007.

PENUEL, William R. et al. Investigating the potential of using social network analysis in educational evaluation. American Journal of Evaluation, Washington, v. 27, n. 4, 2006.

REIS, Nádia Maria Viana. Projeto fortalecimento da gestão escolar: reflexões sobre os desafios e possibilidades vivenciadas na construção progressiva da gestão democrática e da autonomia escolar a partir de uma experiência baiana. In: CONGRESO INTERNACIONAL DEL CLAD SOBRE LA REFORMA DEL ESTADO Y DE LA ADMINISTRACIÓN PÚBLICA, 8., 2003, Panamá. Anais... Panamá: [s.n.], 2003.

SOUZA, Celina. Políticas públicas: conceitos, tipologias e sub-áreas. São Paulo: [s.n.], 2002.

TSAI, Wenpin; GHOSHAL, Sumantra. Social capital and value creation: the role of intrafirm networks. Academy of Management Journal, Briarcliff Manor, v. 41, n. 4, 1998.

TURNER, Dawn-Marie; HALLENCREUTZ, Jacob; HALEY, Helen.Leveraging the value of an organizational change management methodology. The International Journal of Knowledge, Culture and Change Management, Champaign, v. 9, n. 9, 2009.

WASSERMAN, Stanley; FAUST, Katherine. Social network analysis: methods and applications. New York: Cambridge University Press, 1998.

WOHLSTETTER, Priscilla; MOHRMAN, Susan Albers. School-based management: strategies for success. [s.1.: s.n.], 1993. Disponível em: <http://www.edfordemocracy.org/ MAHS/Site $\% 20$ based $\% 20 \mathrm{mgt} \% 20-\% 20$ USC.doc $>$. Acesso em: 26 abr. 2009.

YIN, Robert K. Estudo de caso: planejamento e métodos. Tradução de Daniel Grassi. 3. ed. Porto Alegre: Bookman, 2005.

\section{NotAS}

\footnotetext{
1 Para leitura do mencionado regimento, ver Bahia (1997, 2010).

2 UCINET é uma ferramenta para análise de redes sociais, desenvolvido por Steve Borgatti, Martin Everett e Linton Freeman, que é distribuído pela empresa Analytic Technologies.

3 NetDraw é um software desenvolvido por Steve Borgatti, que serve para visualização de redes e reconhece os dados gerados pelo UCINET. Esse software também é distribuído pela empresa Analytic Technologies.
}

Artigo recebido em janeiro 2013.

Aprovado em novembro 2013. 